\title{
RANCANGAN PERBAIKAN SISTEM KERJA BERDASARKAN KRITERIA 5S PADA INDUSTRI RUMAH TANGGA SEPATU
}

\author{
Yanti Sri Rejeki $^{1}$, Eri Achiraeniwati ${ }^{2}$, Nur Rahman As'ad ${ }^{3}$, Ricky Gunawan $^{4}$ \\ Jurusan Teknik, Industri, Fakultas Teknik, Universitas Islam Bandung ${ }^{1,2,3,4)}$ \\ Jl. Tamansari No. 20 Bandung, Jawa Barat 40116 \\ E-Mail : yanti.srirejeki@unisba.ac.id ${ }^{1}$,eri.achiraeniwati@unisba.ac.id ${ }^{2}$, \\ nur.rahman@unisba.ac.id ${ }^{3}$,Ricky.16071993@gmail.com ${ }^{4}$
}

\begin{abstract}
Cibaduyut is a shoe industry center area, located in Bandung city, West Java. This industry is required to be able to improve productivity and quality assurance of footwear produced to be able to compete with other similar companies. Generally, based on observations in previous research, the condition of the craftsmen works with simple equipment in a work environment that does not meet the requirements of an ergonomic working system that meets the requirements of effective, convenient, safe, healthy and efficient. Several improvements have been made to improving facilities, environments and working methods. These improvements still seem less effective and efficient because the work culture is still irregular. Based on the above, it is necessary to improve the work culture with the $5 S$ method in every work station / process thoroughly and systematically so as to form a good working moral movement through the process of education, forming habits, discipline and building mindset of workers who support productivity effective, comfortable, safe, healthy and efficient, so that Cibaduyut shoe will able to compete in the future.
\end{abstract}

Keywords : Work Culture, 5S, Ergonomics, ENASE.

\section{PENDAHULUAN}

Sentra industri sepatu Cibaduyut yang terbentuk sejak tahun 1920 sampai saat ini masih mampu bertahan dengan jumlah pengrajin sepatu Cibaduyut berjumlah sekitar 600 pengrajin dengan rata - rata produksi 800.000 pasang sepatu per bulan dengan omzet mencapai Rp. $25 \mathrm{M}$. Jumlah pengrajin yang terus berkurang dari jumlah awal sekitar 5.000 pengrajin (Yulianto, Agung, 2012). Secara umum berdasarkan hasil pengamatan pada penelitian terdahulu kondisi para pengrajin bekerja dengan alat yang sederhana pada lingkungan kerja yang tidak memenuhi syarat sistem kerja yang yang ergonomis yang memenuhi syarat efektif, nyaman, aman, sehat dan efisien (ENASE).

Hal tersebut disebabkan berbagai faktor diantaranya tingkat pemahaman yang rendah terhadap prinsip bekerja secara sehat dan aman (Sri Rejeki, Y dkk, 2012). Oleh karena itu, dibuat rancangan sistem kerja yang ergonomis untuk meminimasi beban fisik dan mental pekerja, dengan membuat standar fasilitas, metode dan lingkungan fisik kerja yang ergonomis (Sri Rejeki, Yanti, As'ad, Achiraeniwati, 2014). Berdasarkan pengamatan pada saat implementasi, sistem kerja mengalami perbaikan dari segi keamanan dan kenyamanan kerja, tetapi pekerjaan masih terlihat kurang efektif dan efisien dikarenakan budaya kerja yang masih tidak teratur. Hal - hal yang menyebabkan pekerjaan menjadi tidak efektif dan efisien, terlihat dari beberapa faktor, yaitu :

- Manusia

Manusia merupakan komponen yang berpengaruh besar terhadap keberhasilan kerja. Pada industri rumah tangga sepatu cibaduyut, pekerja memiliki keterampilan yang beragam, pendidikan rendah, kedisiplinan rendah, dan budaya kerja yang tidak teratur.

- Fasilitas Kerja

Fasilitas kerja merupakan alat-alat kerja yang digunakan dalam proses pembuatan sepatu. Alat-alat tersebut disimpan tidak beraturan, yang menyebabkan adanya proses mencari alat kerja dalam proses 
produksinya. Hal ini mengakibatkan pekerjaan menjadi tidak efektif. Selain itu tidak terawatnya fasilitas kerja yang digunakan.

- Material

Material atau bahan baku utama yang digunakan untuk membuat sepatu berukuran besar, berbentuk roll kain. Material tersebut disimpan pada tempat yang tidak tetap dikarenakan tempat kerja tidak mempunyai gudang bahan baku. Hal ini mengakibatkan ruangan menjadi tidak rapih.

- Metode Kerja

Pekerja belum sepenuhnya dapat bekerja sesuai dengan standar yang dibuat karena pekerja masih beradaptasi dengan standar kerja tersebut.

- Lingkungan Kerja

Lingkungan kerja tidak bersih dan rapi, dikarenakan ketidakteraturan penyimpanan alat kerja dan bahan baku serta ukuran ruang kerja yang terbatas.

Berdasarkan hal tersebut maka diperlukan suatu perbaikan terhadap budaya kerja dengan aplikasi 5S pada setiap stasiun kerja / proses secara menyeluruh dan sistematis sehingga terbentuk gerakan moral kerja yang baik melalui proses pendidikan, membentuk kebiasaan, disiplin dan membangun pola pikir para pekerja yang mendukung produktivitas kerja yang Efektif, Nyaman, Aman, Sehat dan Efisien (ENASE), sehingga pengrajin sepatu Cibaduyut mampu bersaing dengan baik di masa yang akan datang. Adapun tujuan dari penelitian ini adalah untuk mengidentifikasi budaya kerja saat ini berdasarkan kriteria $5 \mathrm{~S}$ dan membuat perbaikan berdasarkan kriteria tersebut.

\section{METODE PENELITIAN}

Perancangan perbaikan sistem kerja berdasarkan kriteria 5S dilakukan melalui beberapa tahapan, yaitu identifikasi budaya kerja saat ini berdasarkan kriteria 5S, identifikasi kesesuaian budaya kerja saat ini dengan kriteria 5S, pengelompokan perbaikan, dan perancangan perbaikan sistem kerja.
- Identifikasi budaya kerja dilakukan dengan tujuan untuk mengetahui budaya kerja yang ada saat ini. Identifikasi ini dilakukan dengan observasi langsung ke lapangan untuk melihat dan mengevaluasi secara langsung kondisi lingkungan kerja, metode kerja, bahan dan alat yang digunakan.

- Identifikasi kesesuaian budaya kerja saat ini dengan kriteria 5S, dilakukan dengan observasi lapangan, menggunakan Check Sheet yang dibuat terlebih dahulu. Check Sheet ini dibuat berdasarkan kriteria 5S, dengan indikator dari setiap kriteria tersebut.

- Hasil dari observasi lapangan pada tahapan identifikasi selanjutnya dikelompokan berdasarkan 5S. Pengelompokan ini dijadikan sebagai dasar dalam membuat perancangan sistem kerja berdasarkan kriteria $5 \mathrm{~S}$.

- Perancangan sistem kerja dibuat berdasarkan hasil pengelompokan perbaikan berdasarkan kriteria-kriteria 5S.

\section{PEMBAHASAN}

Pada tahapan identifikasi budaya kerja saat ini, diperlukan data mengenai proses produksi, alat dan fasilitas kerja yang digunakan, alat kebersihan, perlengkapan kesehatan dan keselamatan kerja, serta kondisi lingkungan pada setiap stasiun kerja. Pada umumnya industri rumah tangga sepatu di Cibaduyut ini memiliki banyak kesamaan dalam hal proses produksi, metode kerja, dan lingkungan kerja. Tahapan proses produksi mulai dari pola, jahit upper, sol, dan finishing. Semua tahapan dilakukan didalam ruangan yang sama, kecuali tahap jahit upper yang biasanya dilakukan ditempat terpisah.

\subsection{Stasiun Kerja Pola}

Pada stasiun ini terdiri dari tiga (3) proses pemolaan bahan baku yaitu pemolaan upper, insol, dan aksesoris. Proses pemolaan dilakukan diatas meja pola, yang dilengkapi dua laci sebagai tempat penyimpanan alat alat yang digunakan untuk proses ini. Pada kenyataannya laci tidak berfungsi dengan baik, hal ini dapat dilihat dari banyaknya 
benda - benda yang tidak diperlukan berada di laci tersebut. Penempatan alat - alat yang dibutuhkan dalam proses ini masih bercampur, sehingga saat diperlukan terdapat proses mencari. Hal ini menyebabkan waktu proses pola menjadi lebih lama. Alat - alat yang digunakan dalam proses pola adalah pensil, gunting, pola lapis / insol, pola pita, pola badan, penggaris, pola belakang, upper, dan insol.

\subsection{Stasiun Kerja Pemolaan}

Stasiun kerja pengesolan merupakan stasiun kerja yang berfungsi untuk proses perakitan dari setiap komponen sepatu. Komponen yang dirakit pada stasiun pengesolan ini adalah bagian upper, insol, dan aksesoris. Penempatan komponen komponen dan alat kerja yang digunakan pada staiun kerja ini belum tertata dengan baik. Meja kerja sol yang telah dibuat berdasarkan hasil rancangan perbaikan, belum berfungsi dengan baik. Masih terdapat alat dan bahan yang tidak diperlukan berada pada area stasiun kerja, dan pekerja masih tidak menggunakan masker pada saat bekerja. Peralatan yang digunakan pada stasiun kerja ini adalah palu, gegep, pisau, gunting, lem tarik, lem sol, lem KA untuk Upper, paku besar, tarilan jadi, sulas, insol, upper yang telah dijahit, paku kecil, dan sol.

\section{- $\quad$ Stasiun Kerja Finishing}

Stasiun kerja finishing merupakan stasiun kerja yang berfungsi untuk proses finishing dan pengepakan. Meja kerja finishing hasil rancangan dilengkapi dengan tiga laci untuk penyimpanan alat - alat kerja, dan rak rak yang berfungsi sebagai penyimpanan sepatu serta perlengkapan lainnya. Meja tersebut belum berfungsi secara optimal. Hal ini dapat dilihat dari penempatan alat kerja tidak beraturan. Stasiun kerja finising dan pengesolan berada dalam ruangan yang sama, oleh karena itu kondisi lingkungan kerja pada stasiun finishing hampir sama dengan stasiun pengesolan. Penempatan peralatan dan bahan baku yang masih tidak beraturan, sekitar stasiun kerja finishing kotor, terdapat alat dan bahan yang tidak diperlukan berada pada area stasiun kerja, banyaknya bahan berbahaya yang terdapat di meja stasiun kerja finising, seperti lem. Peralatan yang digunakan pada stasiun kerja ini adalah kardus sepatu, sepatu, lem, sikat lem, kain, botol berisi bensin, dan sablon cap / merk.

Tahapan selanjutnya adalah identifikasi kesesuaian budaya kerja saat ini dengan prinsip 5S bertujuan untuk mengetahui kesesuaian budaya kerja saat ini dengan kriteria Seiri (pemilahan), Seiton (penataan), dan Seiso (Pembersihan). Identifikasi hanya dilakukan pada tiga kriteria tersebut, karena dua kriteria lainnya, yaitu seiketsu dan shitsuke merupakan tahapan lanjutan dari tiga kriteria yang telah diimplementasikan.

\section{- Seiri (Pemilahan)}

Seiri merupakan suatu aktivitas pertama dalam pelaksanaan $5 \mathrm{~S}$, yaitu membuang / menyortir / menyingkirkan barangbarang, file - file yang tidak digunakan lagi ketempat pembuangan (Suwondo, C., 2012). Semua barang yang ada di lokasi kerja, hanyalah barang yang benar-benar dibutuhkan untuk aktivitas kerja. Hasil identifikasi terhadap tiga stasiun kerja berdasarkan hasil kriteria seiri adalah sebagai berikut :

- Masih terdapat barang - barang yang tidak digunakan atau diperlukan dalam pekerjaan di sekitar meja kerja. gambar 1 menunjukkan laci pada meja pola yang seharusnya hanya berfungsi sebagai tempat penyimpanan alat-alat kerja, menjadi tempat penyimpanan barang yang lainnya.

- Masih terdapat barang - barang yang tidak diperlukan berada pada areal kerja. Pada Gambar 2 dan 3 dapat dilihat terdapat benda - benda yang tidak diperlukan dalam proses sol dan finishing. 
- Alat-alat kerja ditempatkan dalam satu tempat, sehingga diperlukan proses mencari pada saat akan menggunakan alat tersebut (Gambar 1).

- $\quad$ Seiton (Penataan)

Seiton merupakan aktivitas penataan atau penempatan alat, bahan dan fasilitas kerja. Kondisi kerja yang sesuai dengan kriteria ini adalah setiap barang punya tempat, setiap tempat punya nama untuk barang tertentu, penempatan terorganisir dan sistematis, setiap tempat penyimpanan diberi nama yang mudah diingat, dapat menggunakan kode pada tempat penyimpan. Hasil identifikasi terhadap ketiga stasiun kerja menunjukan bahwa semua stasiun kerja belum memenuhi kriteria ini.

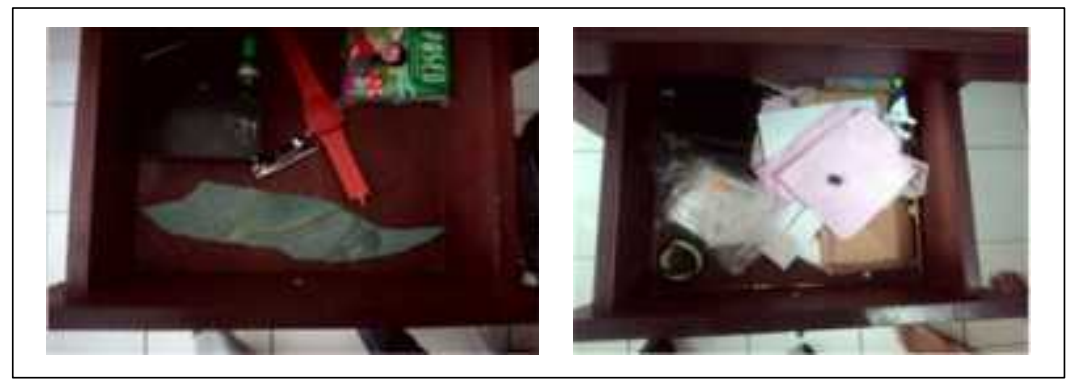

Gambar 1. Kondisi Laci Meja Pola.

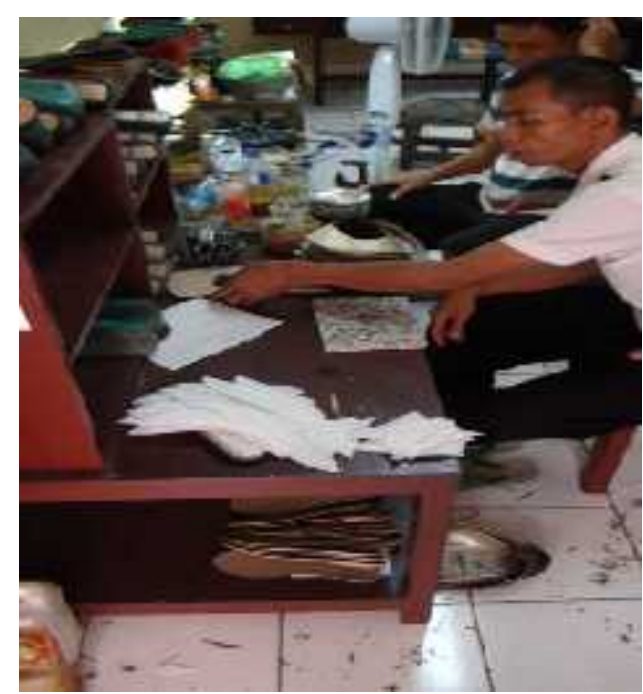

Gambar 2. Kondisi Meja Kerja Sol.

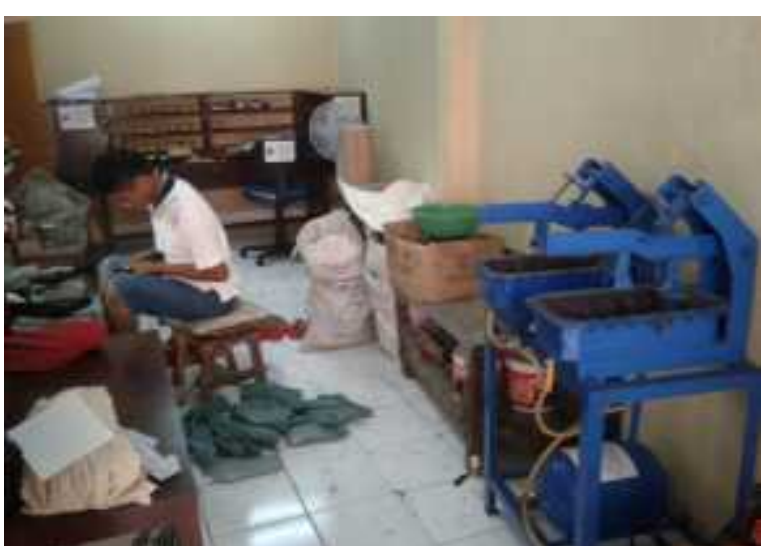

Gambar 3. Kondisi Ruang Kerja Sol dan Finishing. 
Tabel 1. Pengelompokan Perbaikan Berdasarkan 5S

\begin{tabular}{|c|c|c|}
\hline $5 \mathrm{~S}$ & Indikator & Perbaikan \\
\hline Seiri & $\begin{array}{l}\text { Pekerja terbiasa untuk } \\
\text { memilah barang yang } \\
\text { diperlukan dan tidak. }\end{array}$ & $\begin{array}{l}\text { - Membuat daftar alat yang diperlukan. } \\
\text { - Melatih pekerja untuk mengenal barang yang diperlukan } \\
\text { dan tidak. }\end{array}$ \\
\hline \multirow[t]{2}{*}{ Seiton } & $\begin{array}{l}\text { Peralatan / tools tertata } \\
\text { dengan baik pada } \\
\text { setiap stasiun kerja. }\end{array}$ & $\begin{array}{l}\text { - Menyediakan tempat untuk setiap alat dan bahan, sehingga } \\
\text { semua alat dan bahan memiliki tempat khusus. } \\
\text { - } \text { Memberikan nama pada setiap tempat alat dan bahan. } \\
\text { - Menata alat - alat kerja berdasarkan tingkat pemakaian } \\
\text { (sering dan jarang digunakan). }\end{array}$ \\
\hline & $\begin{array}{l}\text { Pekerja terbiasa } \\
\text { melakukan } \\
\text { pembersihan pada } \\
\text { ruang kerjanya. }\end{array}$ & $\begin{array}{l}\text { Menyediakan peralatan kebersihan di setiap stasiun kerja, } \\
\text { seperti tempat sampah, sapu, dan kain pel. } \\
\text { - Menyediakan tempat sampah pada setiap stasiun kerja. }\end{array}$ \\
\hline Seiso & $\begin{array}{l}\text { Pekerja terbiasa } \\
\text { melakukan } \\
\text { pembersihan pada } \\
\text { peralatan yang } \\
\text { digunakan. }\end{array}$ & $\begin{array}{l}\text { - Menyediakan peralatan kebersihan untuk membersihkan } \\
\text { peralatan kerja, seperti kain lap, cairan pembersih. }\end{array}$ \\
\hline Seiketsu & $\begin{array}{lr}\text { Pekerja } & \text { konsisten } \\
\text { melakukan } & \text { tahapan- } \\
\text { tahapan } & 3 \mathrm{~S} \\
\text { sebelumnya. } & \end{array}$ & $\begin{array}{l}\text { - Membuat tanda-tanda peringatan yang sesuai dan jelas } \\
\text { berupa display peringatan. }\end{array}$ \\
\hline Shitsuke & $\begin{array}{l}\text { Pekerja disiplin dan } \\
\text { mentaati peraturan } \\
\text { perusahaan. }\end{array}$ & $\begin{array}{l}\text { - Membuat SOP 5S. } \\
\text { - Memberikan pelatihan. } \\
\text { - } \text { Membuat aturan. }\end{array}$ \\
\hline
\end{tabular}

Hal ini dapat dilihat dari kondisi sebagai berikut :

- Pada stasiun kerja pola, alat kerja sudah ditempatkan pada laci yang terdapat pada meja, akan tetapi penyimpanan masih tercampur (Gambar 1). Hal ini menyebabkan proses mencari pada saat alat akan digunakan.

- Pada stasiun kerja sol, semua alat kerja, bahan dan komponenkomponen yang akan dirakit diletakan diletakan diatas meja (Gambar 2).

- Pada stasiun kerja finishing, alat - alat kerja diletakan diatas meja bercampur dengan sepatu yang akan di finishing (Gambar 4).

- Setiap alat kerja belum memiliki tempat tersendiri, dan belum ada penamaan pada tempat tersebut.
- Seiso (Pembersihan)

Seiso merupakan kegiatan membersihkan tempat kerja, ruangan kerja, peralatan dan lingkungan kerja (Suwondo, C., 2012). Hasil identifikasi pada setiap stasiun kerja berdasarkan kriteria ini adalah sebagai berikut :

- Kegiatan pembersihan pada area kerja tidak dilakukan secara teratur. Pada gambar 2 sampai 3 dapat dilihat banyaknya kotoran sisa produksi yang berceceran dilantai, terdapat debu debu yang menempel pada meja kerja, dinding dan lantai.

- Kegiatan pembersihan pada alat - alat kerja setelah memakai peralatan tersebut tidak dilakukan. 
Tabel 2. Alat dan Bahan yang digunakan

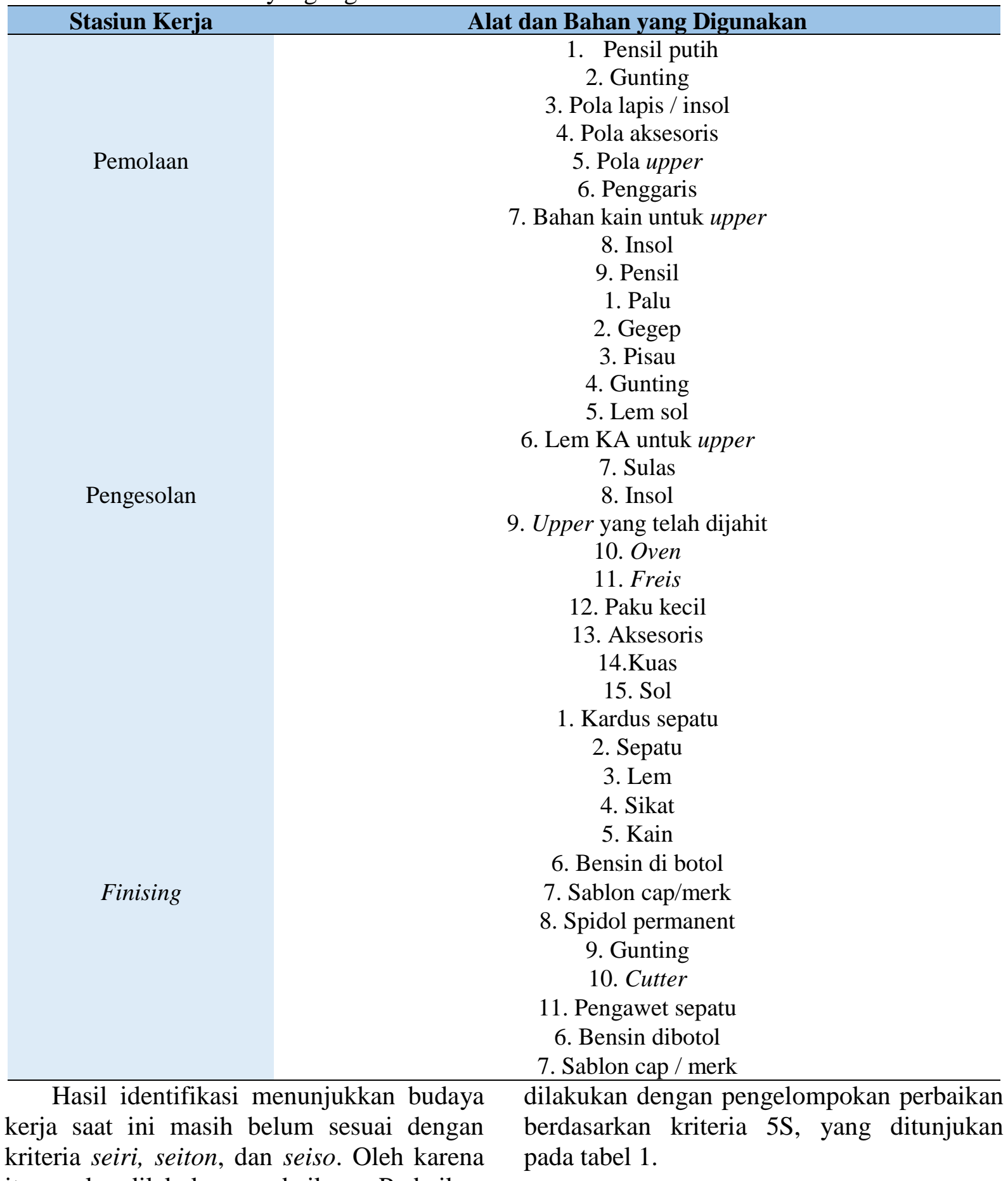

itu perlu dilakukan perbaikan. Perbaikan

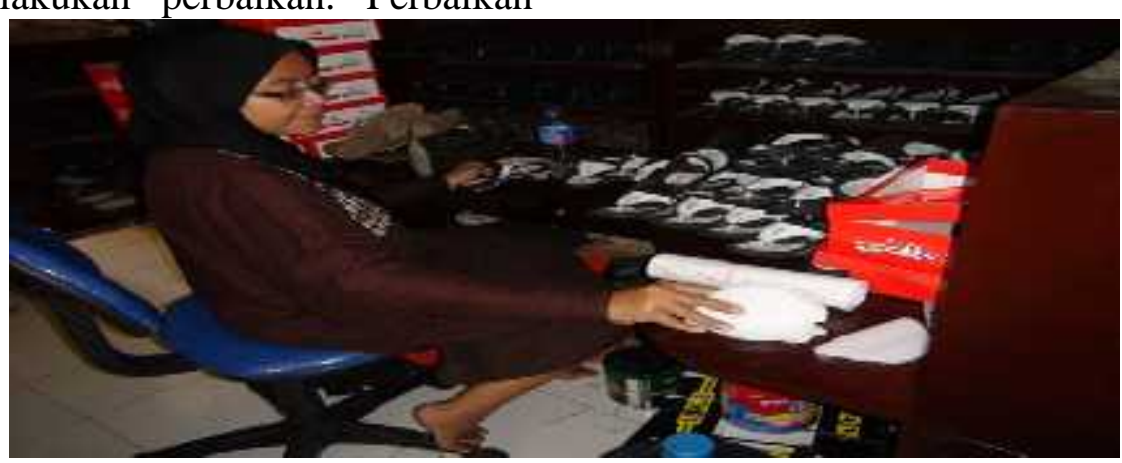

Gambar 4. Kondisi Meja Finishing. 
Tabel 3. Frekuensi Pemakaian Alat Pada Meja Pola

\begin{tabular}{cc}
\hline Frekuensi pemakaian & Alat yang digunakan \\
\hline \multirow{2}{*}{ Sering } & Pensil Putih \\
& Gunting \\
& Penggaris \\
Jarang & Pensil \\
& Pola Upper \\
& Pola Insol \\
\hline
\end{tabular}

Tabel 4. Frekuensi Pemakaian Alat Pada Stasiun Kerja Pengesolan

\section{Frekuensi pemakaian}

Sering

Jarang

\section{Alat yang digunakan}

Palu

Gegep

Lem Sol

Sulas

Paku Kecil

Upper yang Telah Dijahit

Insol

Aksesoris

Sol

Oven

Freis

Lem KA

Pengungkit
- Seiri (Pemilahan)

Pada aktivitas ini, pekerja harus terbiasa untuk memilah barang yang diperlukan dan tidak. Oleh karena perlu dilakukan :

- Membuat daftar alat dan bahan yg diperlukan pada setiap proses (Tabel 2), sehingga pekerja tidak kebingungan dalam menetapkan tingkat kepentingan dari alat dan bahan yg diperlukan.

- Melatih pekerja untuk mengenal barang yang diperlukan dan tidak pada masing-masing stasiun kerja.

\section{- Seiton (Penataan)}

Tujuan dari seiton adalah peralatan/tools tertata dengan baik pada setiap stasiun kerja sehingga pekerjaan bisa dilakukan dengan efektif. Oleh karena diperlukan tempat untuk setiap alat dan bahan, memberikan nama pada setiap tempat alat dan bahan, dan menata alat - alat kerja berdasarkan tingkat pemakaian (sering dan jarang digunakan).

- Stasiun Kerja Pola

Pada meja kerja pola sudah terdapat tempat penyimpanan alat-alat kerja, yaitu dua laci yang terletak sebelah kiri dan kanan meja. Akan tetapi belum berfungsi dengan optimal, maka perbaikannya adalah dengan membuat sekat - sekat pada laci tersebut, sehingga setiap alat memiliki tempat sendiri. Laci kanan digunakan untuk menyimpan alat yang sering digunakan, dan laci kiri berfungsi untuk menyimpan alat yang jarang digunakan. Oleh karena itu dilakukan identifikasi terhadap frekuensi penggunaan alat (Tabel 3). Berdasarkan tabel 3, maka laci kanan dibuat menjadi empat tempat untuk menyimpan pensil putih, gunting, penggaris dan pensil, sedangkan laci kiri dibuat menjadi tiga tempat untuk menyimpan pola upper, insol, dan 
Tabel 5 Frekuensi Pemakaian Alat Pada Meja Finising

\section{Frekuensi Pemakaian}

\begin{tabular}{cc}
\hline & 1. Kardus Sepatu \\
& 2. Sepatu \\
& 3. Lem \\
4. Sikat & 5. Kain \\
Sering & 6. Bensin Di Botol \\
& 7. Sablon Cap / Merk \\
8. Spidol Permanent & 9. Gunting \\
10. Cutter \\
11. Pengawet Sepatu
\end{tabular}

aksesoris. Selanjutnya dilakukan pelabelan untuk setiap laci yang terdapat pada meja pola. Pembuatan palabelan pada laci, akan memberikan kemudahan bagi pekerja untuk mengambil alat yang akan digunakan.

\section{- Stasiun Kerja Sol}

Tidak tersedianya tempat untuk penyimpanan alat yang digunakan, membuat para pekerja meletakan alat yang digunakan pada meja pengesolan yang akan digunakan. Setelah melakukan identifikasi kesesuain dan uraian mengenai rancangan perbaikan yang akan dilakukan pada aktifitas ini, maka harus disediakan tempat penyimpanan untuk alat - alat yang akan digunakan, sehingga alat yang digunakan memiliki tempat sendiri. Penataan peralatan perlu dilakukan perbaikan sesuai dengan frekuensi pemakainnya (Tabel 4). Alat yang sering digunakan disimpan pada tempat-tempat yang disimpan di depan operator.

\section{- Stasiun Kerja Finishing}

Pada meja kerja finising terdapat tiga laci, yang terletak dikanan, tengah, dan kiri meja. Penataan peralatan kerja masih belum tertata rapi, masih terdapat alat yang disimpan di atas meja. Frekuensi penggunaan alat pada stasiun kerja ini termasuk sering (Tabel 5). Kardus sepatu dan sepatu disimpan pada rak yang terletak diatas meja, gunting dan cutter disimpan dilaci kanan, spidol dan kain lap dilaci kiri, sedangkan lem, sikat, sablon, spidol, pengawet sepatu disimpan dilaci tengah.

- Seiso (Pembersihan)

Pada tahapan seiso, pekerja harus terbiasa melakukan pembersihan pada alat dan ruang kerjanya. Oleh karena itu perlu tersedia peralatan kebersihan untuk setiap stasiun kerja Peralatan kebersihan untuk stasiun kerja berfungsi untuk melakukan perawatan terhadap stasiun kerja yang dipakai. Hal ini dilakukan agar fasilitas kerja yang digunakan tidak berdebu, tidak kotor, terlihat rapi, bersih dan akan memiliki umur fasilitas yang cukup panjang. Peralatan kebersihan untuk stasiun kerja terdiri dari :

- Kuas.

- Sapu kecil.

- Kanebo.

- Kemoceng.

- Pengki kecil. 
Sedangkan peralatan kebersihan untuk area kerja pemolaan dimana alat alat tersebut terdiri dari :

- Sapu.

- Pel lantai.

- Pengki.

- Ember pel.

Semua peralatan tersebut disimpan pada tempat yang tetap.

\section{- Seiketsu (Pemantapan)}

Tahap ini merupakan tahapan pemantapan dari Seiri, Seiton, dan Seiso. Tahap ini dapat juga disebut tahap perawatan, merupakan standarisasi dan konsistensi dari masingmasing individu untuk melakukan tahapan-tahapan sebelumnya [5]. Untuk tahapan ini dibuat tanda-tanda peringatan yang sesuai dan jelas berupa display peringatan. Display ini merupakan himbauan untuk para pekerja tentang aktifitas dan kebiasaan yang harus dilakukan, baik saat dalam keadaan sebelum bekerja, saat bekerja maupun setelah bekerja.

- Shitsuke

Pemeliharaan kedisiplinan pribadi meliputi suatu kebiasaan dan pemeliharaan program 5S yang sudah berjalan (Suwondo, C., 2012). Rancangan pada tahapan ini dibuat SOP $5 \mathrm{~S}$ untuk setiap stasiun kerja, memberikan pelatihan, dan membuat aturan. Pembuatan SOP dilakukan agar setiap metode kerja pada aktifitas sebelumnya dapat berjalan dengan baik dan terus menurus dilakukan. Dengan adanya standar operasional prosedur pekerja mengerti apa yang akan dilakukan sebelum melakukan pekerjaan, saat melakukan pekerjaan, dan setelah melakukan pekerjaan. Selain itu dibuat hukuman untuk setiap karyawan yang melanggar aturan yang berlaku di perusahaan. Hal ini dilakukan agar karyawan dapat mentaati aturan yang berlaku pada perusahaan terutama tentang, kerapihan, kebersihan, dan kedisiplinan. Hukuman yang berlaku untuk karyawan yang melanggar aturan perusahaan berupa surat peringatan.

\section{KESIMPULAN}

Adapun kesimpulan yang dapat diambil dari hasil pengolahan data dan pembahasan yang telah dilakukan adalah sebagai berikut :

1. Hasil identifikasi budaya kerja saat ini berdasarkan kriteria $5 \mathrm{~S}$, adalah sebagai berikut :

- Seiri : Masih terdapat alat dan barang yang tidak diperlukan berada pada stasiun kerja. Kurangnya kesadaran akan kebersihan dalam bekerja.

- Seiton : Penyimpanan bahan dan alat tidak tersusun dengan rapi, Tidak adanya penataan peralatan di area kerja. Kurangnya kesadaran pekerja dalam penataan peralatan di tempat yang telah disediakan.

- Seiso : Masih terdapat pekerja yang membuang sampah tidak pada tempatnya. Tidak menata.

- Kembali alat yang sudah digunakan seperti pada keadaan seperti sebelum bekerja. Tidak adanya pembersihan alat secara berkala.

- Seiketsu : Pekerja tidak menggunakan masker saat bekerja, Masih terdapat pekerja yang merokok di area kerja, Pekerja dating tidak tepat pada waktu yang telah ditentukan perusahaan.

- Shitsuke : Tidak adanya peraturan tertulis tentang pelanggaran yang dilakukan oleh pekerja.

2. Identifikasi kesesuaian budaya kerja saat ini dengan prinsip 5S, menunjukan bahwa budaya kerja saat ini masih belum sesuai dengan kriteria $5 \mathrm{~S}$.

3. Hasil rancangan perbaikan metode kerja adalah sebagai berikut : 
- Rancangan seiri pada seluruh stasiun kerja adalah melakukan pemilahan terhadap setiap alat, bahan baku, dan sampah-sampah baik yang memiliki nilai tambah ataupun tidak, menyediakan tempat penyimpanan untuk setiap alat, bahan baku, dan komponen yang telah jadi.

- Rancangan seiton pada seluruh stasiun kerja adalah menetukan frekuensi pemakaian barang setiap stasiun, menetapkan tempat penyimpanan barang-barang setiap stasiun dan membuat gambar rancangan penataan area kerja. Dengan ditatanya peralatan akan meningkatkan produktivitas dengan menghilangkan waktu yang dibutuhkan untuk mencari sesuatu.

- Rancangan seiso pada seluruh stasiun kerja adalah menyediakan peralatan kebersihan, tersedianya penempatan alat kebersihan. Dengan lingkungan yang bersih para pekerja akan merasa nyaman dalam bekerja.

- Rancangan seiketsu untuk seluruh stasiun kerja adalah pembuatan display. Display ini merupakan himbauan untuk para pekerja tentang aktifitas dan kebiasaan yang harus dilakukan, baik saat dalam keadaan sebelum bekerja, saat bekerja maupun setelah bekerja.

- Hasil rancangan shitsuke untuk seluruh stasiun kerja adalah dengan pembuatan standar operasional prosedur berdasarkan kriteria 5S, membuat aturan dan memberikan hukuman untuk setiap karyawan yang melanggar aturan yang berlaku diperusahaan, dan melakukan pengarahan serta pengontrolan mengenai $5 \mathrm{~S}$.

\section{Ucapan Terimakasih}

Ucapan terimakasih kepada Direktorat Jenderal Perguruan Tinggi (DIKTI), yang telah membiayai penelitian ini.

\section{DAFTAR PUSTAKA}

Osada,T., 2004. Sikap Kerja 5S, Cetakan kelima, Penerbit PPM, Jakarta.

Sri Rejeki, Y., As'ad, N., Achiraeniwati, E., Lovione, A., 2012, Usulan Perbaikan Metode Kerja Pada Stasiun Kerja Pola Dengan Motion Economy Checklist (Studi Kasus Industri Rumah Tangga Sepatu Cibaduyut “ $X$ ”), Seminar Nasional Penelitian dan Pengabdian Masyarakat (SNaPP), 13 November 2012, ISSN 2089-3590.

Sri Rejeki, Yanti, As'ad, Achiraeniwati, 2014, Perbaikan Sistem Kerja Pada Industri Rumah Tangga sepatu di Cibaduyut untuk Meminimasi Beban kerja Mental, Industrial Engineering Conference IDEC 2014, Teknik Industri UNS Solo.

Suwondo, C., 2012. Penerapan Budaya Kerja Unggulan $5 s$ (Seiri, Seiton, Seiso, Seiketsu, Dan Shitsuke) Di Indonesia, Jurnal MAGISTER MANAJEMEN Vol. 1 No. 1, April 2012 29 www.ejurnal.asmi.ac.id.

Yulianto, Agung., 2012. Cibaduyut Produksi 800.000 Sepatu Per bulan, [On Line], http://www.tribunnews.com/2012/0 6/26/cibaduyut-produksi-800-ribusepatu-per-bulan, [diakses 26 Juni 2012]. 